\title{
Impacts of Express Bus Service on Passenger Demand
}

\author{
Jeffrey M. Casello, Ph.D., P.E. \\ Bruce Hellinga, Ph.D., P.Eng. \\ University of Waterloo
}

\begin{abstract}
The Region of Waterloo, Ontario, is a rapidly-growing metropolitan area approximately $100 \mathrm{~km}$ west of Toronto. In 2005, the Region's transit operator, Grand River Transit, introduced an express bus service, known as iXpress, along the central northsouth corridor of the Region. This paper explores the impact of the iXpress service on transit user costs and passenger attraction. We employ a methodology to quantify the generalized cost (including waiting time, in-vehicle and transfer times) of transit trips between key destinations in the Region before and after the implementation of iXpress. We also develop a methodology to identify those customers who benefit from the reduced cost of the iXpress. Finally, we present the change in ridership (boardings) in the corridor pre-and post-implementation. From these demand and cost data, we compute transit elasticity of demand with respect to generalized cost.
\end{abstract}

\section{Introduction}

The Region of Waterloo, ${ }^{1}$ located approximately $100 \mathrm{~km}$ west of Toronto in southern Ontario, comprises three cities-Kitchener, Waterloo and Cambridge-and four rural townships. The Region has a population of approximately 500,000 but is expected to reach 730,000 by 2031 (Region of Waterloo 2003.) Commensurate job growth is also predicted. In response to these growth pressures, the Region of Waterloo (2003) developed a Regional Growth Management Strategy (RGMS) to 
manage the locations of new homes and jobs and to provide suitable transportation alternatives. A principle component of the RGMS is a balanced transportation system that promotes multimodal travel options and leads to intensified land uses. One major investment in the Region's Grand River Transit (GRT) has been the introduction of an express bus service, known as iXpress, connecting major activity centers along the region's central north-south corridor.

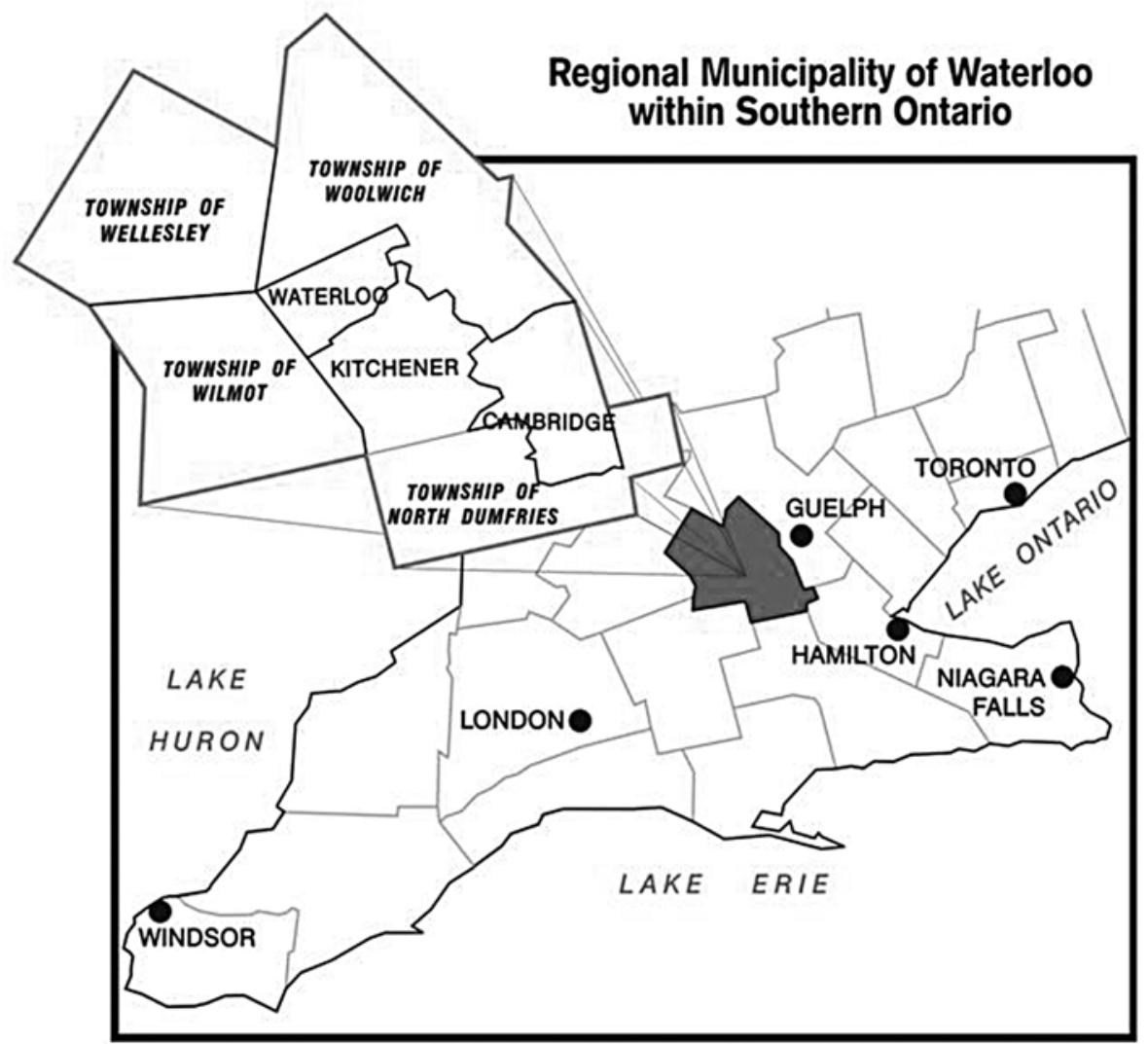

Figure 1. Location and Composition of the Regional Municipality of Waterloo in Southern Ontario

This paper develops and applies a methodology to analyze the impacts of the iXpress on travel costs and ridership in an existing transit corridor. We compute the differences in generalized costs (including waiting time, in-vehicle time, and transfer time) for travel between major activity centers in the Region before and after the introduction of iXpress. We define and apply a methodology to identify transit customers who benefit from the introduction of the iXpress service. We 
also present the number of boardings in a service corridor that took place pre- and post-implementation of the iXpress service. Based on the reduction in generalized cost and increase in ridership, we compute the elasticity of transit demand with respect to generalized cost.

The remainder of the paper is structured as follows. The following section presents a literature review of generalized cost formulations and elasticity models for analyzing transit demand. In the third section, further detail is provided on the Region of Waterloo and the iXpress service. Section four presents the methodology used in computing generalized costs and applies that method to the case study. Elasticities are presented. In section five, the results of elasticity computations are analyzed and the shortcomings of elasticity models are presented. Section six presents conclusions and suggestions for further research.

\section{Literature Review}

The concept of utility theory suggests that consumers choose an alternative that possesses a set of characteristics that maximizes the benefit derived by the consumer (Lancaster 1966). Transportation studies often assume that travelers derive no utility from the trip itself, but rather travel to achieve other goals (i.e., work, shopping, education etc.) Thus, travel consumers are modeled not as utility maximizers, but instead as disutility (or generalized cost) minimizers. Disutility of transit travel has the following components (Kittelson and Associates 2003): access time to transit service, waiting time, in-vehicle time, transfer times (where applicable), egress times, and fares. Typically, the relative contribution to overall disutility of these individual attributes is expressed by a weighted, linear sum of the attributes (Ortuzar and Williamson 2001). For example, most studies suggest that passengers perceive waiting time and transfer time to be more onerous than in-vehicle travel times.

Utility theory has long been used in mode choice models to predict transit ridership. When choosing between competing modes (typically transit and auto), a traveler's propensity to choose a given mode is a function of the relative generalized costs, or disutility, of the competing modes. Often, logit or probit models are used to compute the probability of choosing a mode amongst a set of candidate modes based on a comparison of their generalized costs (Ben Akiva and Leman 1985). These models often are employed at the regional level as part of travel forecasting work. 
Utility models have been employed to assess the impacts of potential changes in transit services on transit ridership in regional corridors. Examples of this type of study include Kopp et al. (2006) in Chicago and Casello (2007) in Philadelphia. The benefits of corridor-level analysis are that it allows for a more detailed representation of transit costs than is possible when working at a regional level and requires significantly less data and computational effort. As such, corridor-level analysis may be feasible for transit agencies to complete in-house, thereby reducing reliance on consultants or external travel models.

The output of corridor level analysis may also be elasticities of demand with respect to generalized cost that may be assumed to be valid within the study area. The use of elasticities to predict changes in travel habits has been studied extensively. A comprehensive reference list of such studies is presented by Taylor and Miller (2003). In the same paper, the authors present a two stage, least-squares regression that considers the ridership impacts of non-transportation variables (geography, economy, and population) as well as transport variables (auto ownership, fuel prices, transit supply and cost). Their results are consistent with most other studies-that transit supply (positively correlated) and fares (negatively correlated) are both statistically significant predictors of transit ridership, which explain much (in their case, 95\%) of the variation in ridership.

In the current application, the generalized cost, or disutility, of travel is computed without and with the iXpress service. The change in disutility is correlated to changes in ridership through standard elasticity models. Litman (2004) defines short- and long-term elasticities and presents the findings for various inputs (fares, auto costs, income, etc.), modes, and locations. A more sophisticated summary of previous studies is presented by Holmgren (2007), who utilizes a meta-analysis method to draw conclusions about the importance of functional form, data inclusion, data types, and environmental factors on predicted elasticities. Holmgren also presents observed ranges of several demand elasticities (price, supply, income, auto ownership, and fuel prices). Balcombe et al. (2004) present elasticities for various components of generalized costs using UK examples.

Ideally, the travel patterns of individual transit customers could be surveyed and recorded, and changes in behavior in response to changes in transit services could be evaluated on an individual origin-destination basis. This would require extensive data collection that would only be feasible if fully automated, perhaps through smart card fare collection technology. In the absence of smart cards, we suggest that corridor level analysis provides an appropriate balance between data 
requirements and the robustness of the ridership projections. The potential levels of transit analysis are shown in Table 1.

Table 1. Possible Levels of Analysis for Predicting Changes in Ridership as a Result of Transit Service Change

\begin{tabular}{|c|c|c|}
\hline $\begin{array}{l}\text { Spatial } \\
\text { Scale }\end{array}$ & $\begin{array}{c}\text { Data } \\
\text { Requirements }\end{array}$ & $\begin{array}{l}\text { Transit } \\
\text { Outputs }\end{array}$ \\
\hline $\begin{array}{l}\text { Regional } \\
\text { forecasting } \\
\text { models }\end{array}$ & $\begin{array}{l}\text { Disaggregated geographical } \\
\text { zones } \\
\text { Land use data } \\
\text { Full transportation network } \\
\text { representation } \\
\text { Household surveys / facility } \\
\text { volumes for calibration }\end{array}$ & $\begin{array}{l}\text { Mode share (logit formulations) } \\
\text { by O-D zones } \\
\text { Transit assignment } \\
\text { Macro-level changes in mode } \\
\text { split }\end{array}$ \\
\hline $\begin{array}{l}\text { Regional } \\
\text { corridor } \\
\text { analysis }\end{array}$ & $\begin{array}{l}\text { Waiting time estimates } \\
\text { Corridor travel times } \\
\text { Change in corridor demand } \\
\text { (boardings) }\end{array}$ & $\begin{array}{l}\text { Reductions in traveler } \\
\text { generalized costs } \\
\text { Corridor elasticity to GC }\end{array}$ \\
\hline $\begin{array}{l}\text { Micro- } \\
\text { level O-D } \\
\text { analysis }\end{array}$ & $\begin{array}{l}\text { Representative survey of } \\
\text { passenger origins } \\
\text { Transit line access and } \\
\text { egress points } \\
\text { Final destination }\end{array}$ & $\begin{array}{l}\text { O-D level assessment of service } \\
\text { change impacts on ridership }\end{array}$ \\
\hline
\end{tabular}

The current paper builds upon the existing literature in several ways. First, the paper develops and implements a method to analyze comprehensively the change in travel parameters as a result of the proposed transit service upgrades. Second, the paper applies utility theory to compute the changes in generalized costs for trips made between major activity centers. The changes in generalized cost are then compared to observed changes in ridership to compute mid-run elasticities for a specific case. The calculated elasticities are compared to previously published results.

\section{The Region of Waterloo and iXpress service}

Waterloo Region is one of the most diverse and dynamic economic regions in Canada. The area extending from Toronto in the east, Niagara Falls in the south, and the Region of Waterloo in the west is known as the Greater Golden Horseshoe 
(GGH). The GGH is often referred to as the economic engine of Ontario. The entire $\mathrm{GGH}$ is experiencing strong development pressures. The Province of Ontario has produced a strategic plan known as "Places to Grow," which intends to steer development to targeted built-up areas. The Region of Waterloo is one of these areas.

The Region itself is a significant contributor to the national economy, with an annual estimated regional GDP of over $\$ 16$ billion (CDN) derived from a strong mix of agricultural, manufacturing, and service sector employment. A major challenge for the Region in light of the projected growth is to accommodate increased housing and employment lands without diminishing the value of local agricultural activities. Moreover, the Region currently experiences very little congestion. The intention of Regional planners is to develop a balanced, multi-modal transportation system that will both facilitate future travel demands and positively influence land uses (achieve intensification). The iXpress service is a major step towards balanced transportation alternatives in the Region.

\section{iXpress Service}

The iXpress is a limited-stop, express service that travels between Waterloo, Kitchener, and Cambridge. The alignment, shown in Figure 2, is approximately $33 \mathrm{~km}$ in length and consists of 13 stops. Along the route are four downtowns (two in Cambridge), two universities, office complexes, major hospitals, and regional shopping centers. When the iXpress service commenced in September 2005, it operated between 06:45 and 19:00 Monday through Friday, with 15-minute headways during the morning and afternoon peak periods and 30-minute headways during the midday. In the fall of 2007, weekday service was extended to 05:40 and 23:00; Saturday and Sunday services were introduced. The iXpress service is provided using standard 40-foot Nova low-floor buses that are differentiated from buses servicing local routes by unique exterior branding.

Prior to 1999, transit service was operated by two independent providers-one serving Kitchener and Waterloo, the other serving Cambridge. In 2000, the system was unified under a single operator, the Region of Waterloo, which created Grand River Transit. Despite unifying operations, the previous route structure remained. Prior to the introduction of iXpress, no single-seat connections were provided between Cambridge and points north of Fairview Mall; all trips between Cambridge and central Kitchener and Waterloo required a transfer.

In addition to providing regional connectivity, the introduction of iXpress supplemented a local transit route (Route 7) within Kitchener and Waterloo, between 


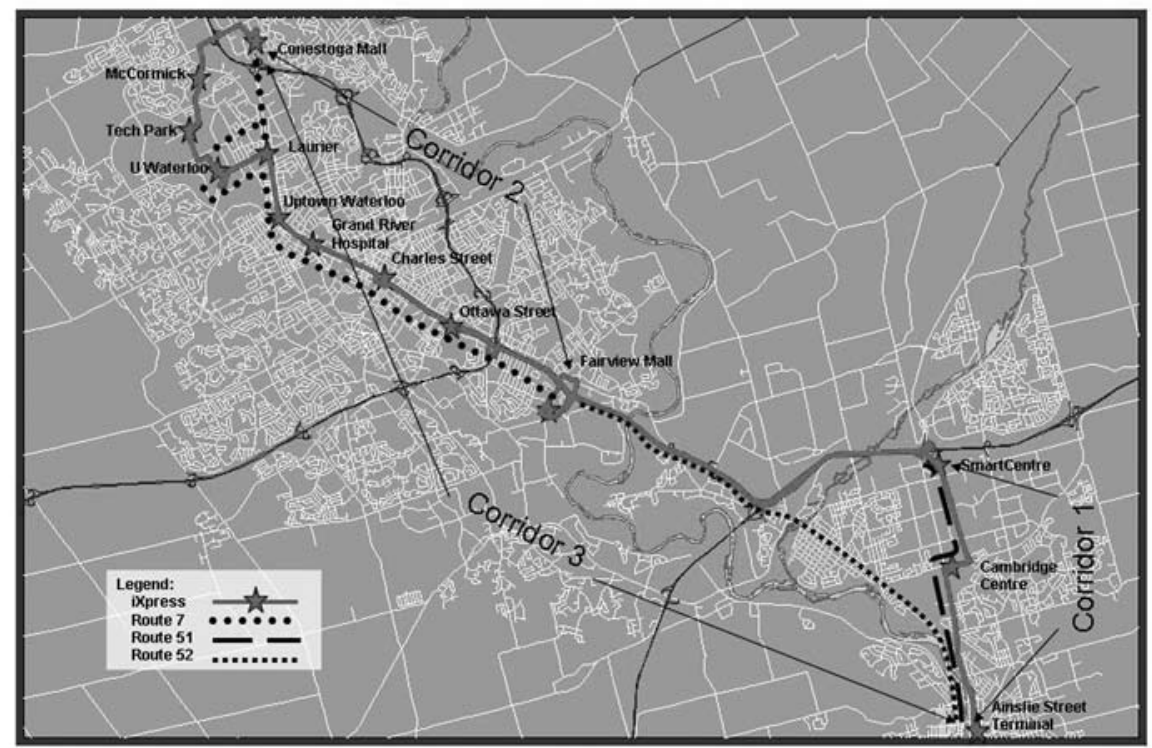

Figure 2. iXpress and Local Routes Connecting Activity Centers in Cambridge, Kitchener and Waterloo

the Fairview and Conestoga Mall iXpress stops. Route 7 is operated with three northern branches - two terminating at the University of Waterloo and one terminating at Conestoga Mall. During peak periods, Route 7 headways on the common section are approximately 5 minutes and 15 minutes for each branch. Note that no direct (single-seat) service is provided by Route 7 from the University of Waterloo to Conestoga Mall. iXpress also supplements two local routes in Cambridge. Route 51 connects three activity centers-the Ainslie, Cambridge Center and Hespler terminals along Hespler Road, a major commercial artery in the Region. Route 52 connects the Ainslie terminal and Fairview Mall via King St. in Cambridge and Highway 8 in Kitchener.

The next sections demonstrate a methodology to quantify the benefits and beneficiaries as a result of the implementation of iXpress.

\section{Methodology}

The goals of this paper are to demonstrate a method to analyze the impacts of express bus service on transit users' costs, to identify those users who benefit from 
these reduced costs, and finally to correlate changes in cost to ridership gains. To estimate the reductions in user costs, we quantify the changes in travel costs for three travel patterns:

1. The corridor between Ainslie St. Terminal and Smartcentres, where the iXpress supplements Route 51 . This represents travel between activity centers within the city of Cambridge.

2. Trips between Ainslie Terminal, Fairview Mall, and all points along the Route 7 alignments. This represents travel between one Cambridge activity center and many activity centers in Kitchener and Waterloo.

3. The corridor between Fairview Mall and Conestoga Mall, including the University of Waterloo, but not Tech Park or McCormick because local service was not previously provided to those stops. This quantifies the improvement as a result of iXpress in the existing Route 7 corridor.

In our case, the introduction of express service affects passengers in the following ways:

- For the travel patterns considered, iXpress operates on the same alignment as local service so that the access and egress times for express service are the same as the local service. We therefore eliminate access and egress time from our generalized cost computations.

- iXpress may increase or decrease passenger waiting times, depending on the frequency of the existing local service in the corridor and the specific origin and destination of the traveler (see section on waiting times, below).

- iXpress reduces in-vehicle times because there are fewer stops than on local service.

- iXpress connects origin-destination pairs directly, eliminating the need for passenger transfers.

Waiting times, in-vehicle times and transfer times are analyzed in detail in the following sections.

\section{Waiting Times}

In calculating passenger waiting times, we make the following assumptions. First, we assume that wait time is correlated to service frequency as follows. For short headways, less than or equal to 10 minutes, we assume random passenger arrivals and an average wait time of $1 / 2$ the headway. For headways greater than 10 minutes, we assume passengers consult schedules, but still allow slightly longer wait times. 
Mathematically, we apply the following continuous functions to compute wait times:

$$
W T=\left[\begin{array}{ll}
\frac{h}{2} & h \leq 10 \\
10-5 e^{\left(1-\frac{h}{10}\right)} & h>10
\end{array}\right]
$$

where: $\quad W T$ is the waiting time in minutes

$h \quad$ is the headway in minutes.

For headways greater than 10 minutes, Equation 1 predicts a wait time that increases as headways increase, but moves asymptotically to a maximum wait time of 10 minutes. This model is very similar to that found empirically by Lam and Morall (1982), as shown in Figure 3. Sensitivity to this waiting time formulation is explored in subsequent sections.

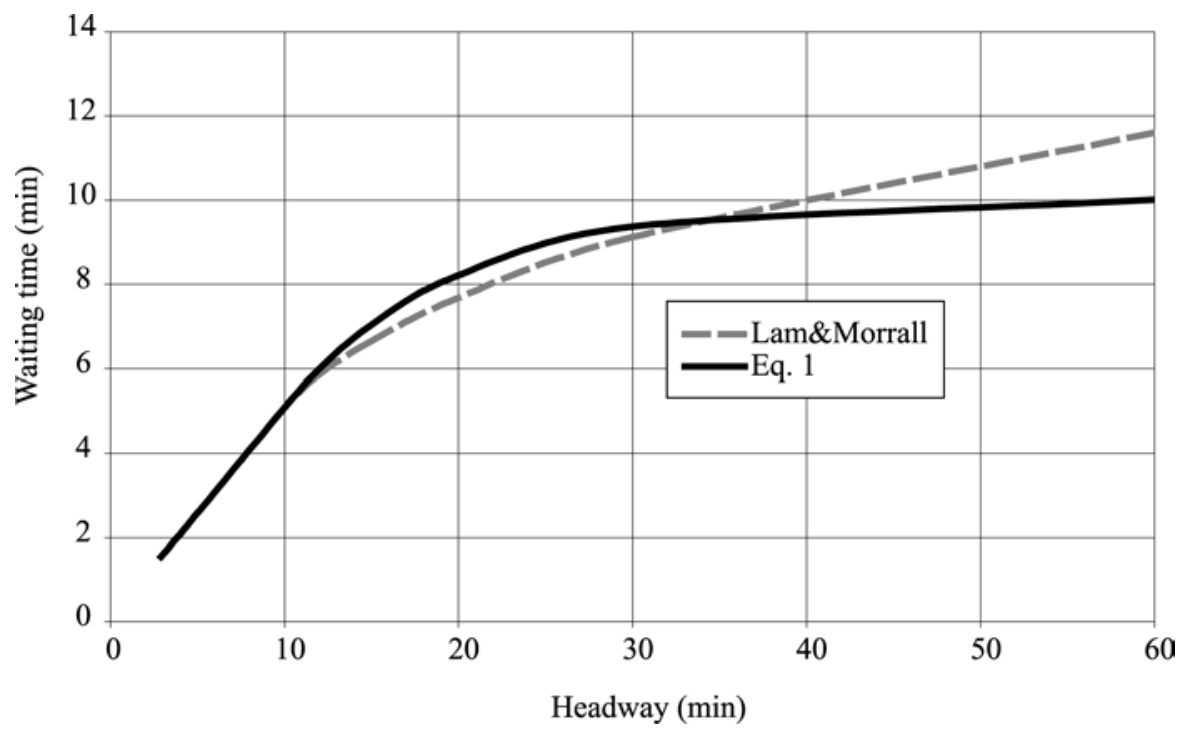

Figure 3. Comparison of Predicting Waiting Times by Lam and Morrall and Eq. 1

In considering traveler behavior, we are faced with three alternatives. We may assume that customers prefer single-seat rides (trips without transfers) and, therefore, extend their wait time for iXpress to avoid a transfer. Alternatively, we may 
assume that customers minimize their wait times by boarding the first arriving vehicle regardless if a transfer is necessary. The third alternative, which we apply in our method, is the assumption that transit customers choose the lowest generalized cost alternative of the previous two choices. This is consistent with oft-cited user equilibrium condition.

\section{Travel Time Analysis}

Because of its limited stops, iXpress has significantly shorter travel time compared to local routes that serve the same alignment. We compute the difference in interstation travel times for trips completed by local routes $(7,51$, and 52$)$ and trips completed by iXpress in each of the travel corridors. Note that this analysis considers only the difference in in-vehicle time; transfer times are considered separately in the next section.

\section{Transfer Times}

The method developed by Vuchic (2005) to estimate average transfer times between two lines with headways $h_{1}$ and $h_{2}$, as presented in Equation 2, is used.

$$
E(T T)=\min \left\{\frac{h_{1}}{2}, \frac{h_{2}}{2}\right\}
$$

Where:

$$
\begin{array}{ll}
\text { E(TT) } & \text { expected (average) transfer time, } \min \\
h_{1} & \text { time headway of originating line, } \min \\
h_{2} & \text { time headway of destination line, } \min
\end{array}
$$

Using Equation 2, we compute the transfer times necessary for local trips that include routes 51 and 7 (transfers at Fairview Mall) and between branches of Route 7 (transfers at Laurier). No transfers are required for trips on the iXpress.

\section{Computing Generalized Cost}

Having computed the changes in each cost component (waiting, in-vehicle and transfer times), generalized costs for travel between all O-D pairs is calculated. The generalized cost, GC, is calculated as shown in Equation 3.

$$
G C_{O D}^{i}=\left(\alpha_{1} W T+\alpha_{2} I V T T+\alpha_{3} T T\right) \frac{V O T}{60}+\text { fare }
$$


Where:

GC generalized cost for travel from origin $O$ to destination $D$ via route $i, \$$

$\alpha_{i} \quad$ relative weight of cost component $i$

WT waiting time, min

INVT in-vehicle travel time, $\min$

TT transfer time, min

VOT value of time, $\$ / \mathrm{hr}$

fare Transit fare, $\$$

Passengers perceive the passage of time differently for each portion of their trip (i.e., wait time at the stop, in-vehicle time, and transfer time). Because we have no local information on the relative weights of the cost components, we utilize the mean values presented in Kittelson et al. (2003, p. 3-20), as shown in Table 2.

\section{Table 2. Relative Weights of Cost Components Used in Generalized Cost Calculations}

\begin{tabular}{|l|c|}
\hline \multicolumn{1}{|c|}{ Cost component } & Value \\
\hline Wait time $\left(\alpha_{1}\right)$ & 2.1 \\
\hline In-vehicle time $\left(\alpha_{2}\right)$ & 1.0 \\
\hline Transfer time $\left(\alpha_{3}\right)$ & 2.5 \\
\hline
\end{tabular}

Many wide-ranging estimates exist for value of travel time in the literature. We use a simple estimate of value of time, $\$ 8$ per hour. Because our analysis involves percent reductions in travel costs, our findings are largely insensitive to the value of time assumption. The GRT pre-paid fare is $\$ 1.40$.

We are primarily concerned with the reduction in generalized costs for passengers after the implementation of the iXpress service. As such, we define the reduction in generalized cost, $\triangle G C$ as:

$$
\Delta G C_{O D}=G C_{O D}^{L}-\min \left[G C_{O D}^{L}, G C_{O D}^{X}\right]
$$


Where: $\quad G C^{L}$ is the generalized cost from $O$ to $D$ via local service, $\$$ $G C^{X}$ is the generalized cost from $O$ to $D$ via iXpress service, $\$$

As noted above, this method assumes that passengers choose the lowest-cost alternative. In the cases where local service is less expensive than iXpress, then we see a zero reduction in generalized cost.

Finally, we compute the percent change in generalized cost as shown in Equation 5:

$$
\Delta G C^{L-X}(\%)=\frac{\Delta G C_{O D}}{G C_{O D}^{L}} 100
$$

\section{Corridor 1 Analysis}

In Corridor 1, existing Route 51 service with a frequency of two buses per hour is supplemented by four iXpress runs per hour. The iXpress also has shorter travel times, saving five minutes between Ainslie Terminal and Cambridge Centre and an additional six minutes between Cambridge Centre and Smartcentres. Neither route requires a transfer. The steps in computing the change in generalized cost are summarized in Table 3.

Because of the reduced in-vehicle and waiting times, the introduction of iXpress reduces generalized costs between these origin-destination pairs by between 22 and 27 percent.

\section{Corridor 2 Analysis}

In Corridor 2, iXpress connects origin-destination pairs that were previously served by Route 7 with high frequency service. As a result, many of the main line station pairs remain best served by local service. Naturally, as the distance traveled increases, the benefits of higher speeds on iXpress offset longer waiting times, and benefits are derived for iXpress trips. For the University of Waterloo, iXpress introduces higher-frequency, direct connections in both the north and southbound directions. Significant reductions in generalized costs are experienced for trips beginning from or destined for the University.

Using the same methodology presented in the Corridor 1 analysis, we compute the reductions in generalized costs as a result of iXpress between origin-destination pairs in Corridor 2. These are shown in Table 4. 


\section{Table 3. Full Methodology for Computing Reduction in Generalized Cost as a Result of iXpress Service}

\begin{tabular}{|c|c|c|c|c|c|c|c|}
\hline \multicolumn{4}{|c|}{ Local Service Only } & \multicolumn{4}{|c|}{ iXpress Service } \\
\hline \multicolumn{8}{|c|}{ In-Vehicle Time (min) } \\
\hline & Ainslie & Cambridge & SmartCentre & & Ainslie & Cambridge & SmartCentre \\
\hline Ainslie Terminal & \begin{tabular}{|l|}
- \\
\end{tabular} & 15 & 28 & Ainslie Terminal & \begin{tabular}{|l|}
- \\
\end{tabular} & \begin{tabular}{|l|}
10 \\
\end{tabular} & 17 \\
\hline Cambridge Centre & 15 & - & 13 & Cambridge Centre & 10 & - & 7 \\
\hline SmartCentre & 28 & 13 & - & SmartCentre & 17 & 7 & - \\
\hline \multicolumn{8}{|c|}{ TU headway (minutes / veh) } \\
\hline Ainslie Terminal & - & 30 & 30 & Ainslie Terminal & - & 15 & 15 \\
\hline Cambridge Centre & 30 & - & 30 & Cambridge Centre & 15 & - & 15 \\
\hline SmartCentre & 30 & 30 & - & SmartCentre & 15 & 15 & - \\
\hline \multicolumn{8}{|c|}{ Expected Wait Time (min) Eq. 1} \\
\hline Ainslie Terminal & - & 9.32 & 9.32 & Ainslie Terminal & - & 6.97 & 6.97 \\
\hline Cambridge Centre & 9.32 & - & 9.32 & Cambridge Centre & 6.97 & - & 6.97 \\
\hline SmartCentre & 9.32 & 9.32 & - & SmartCentre & 6.97 & 6.97 & - \\
\hline \multicolumn{8}{|c|}{ Total Generalized Cost (\$) Eq. 3} \\
\hline Ainslie Terminal & - & 6.01 & 7.74 & Ainslie Terminal & - & $\$ 4.68$ & $\$ 5.62$ \\
\hline Cambridge Centre & $\$ 6.01$ & - & 5.74 & Cambridge Centre & $\$ 4.68$ & - & $\$ 4.28$ \\
\hline SmartCentre & $\$ 7.74$ & $\$ \quad 5.74$ & - & SmartCentre & $\$ 5.62$ & $\$ 4.28$ & - \\
\hline \multicolumn{8}{|c|}{ Reduction in Generalized Cost (\$) Eq. 4} \\
\hline & & & & & Ainslie & Cambridge & SmartCentre \\
\hline & & & & Ainslie Terminal & -1 & $\$ \$ 1.33$ & $\$ 2.13$ \\
\hline & & & & Cambridge Centre & $\$ 1.33$ & - & $\$ 1.46$ \\
\hline & & & & SmartCentre & $\$ 2.13$ & $\$ 1.46$ & - \\
\hline \multicolumn{8}{|c|}{ Reduction in Generalized Cost (\%) Eq. 5} \\
\hline & & & & & Ainslie & Cambridge & SmartCentre \\
\hline & & & & Ainslie Terminal & - & $22 \%$ & $27 \%$ \\
\hline & & & & Cambridge Centre & $22 \%$ & - & $25 \%$ \\
\hline & & & & SmartCentre & $27 \%$ & $25 \%$ & - \\
\hline
\end{tabular}

Table 4. Percent Reductions in Generalized Costs for O-D Pairs in Corridor 2

\begin{tabular}{|l|c|c|c|c|c|c|c|c|}
\hline & Fairview & Ottawa St. & Charles St. & Grand River & Uptown & Laurier & U of W & Conestoga \\
\hline Fairview & - & $0 \%$ & $8 \%$ & $17 \%$ & $16 \%$ & $15 \%$ & $29 \%$ & $11 \%$ \\
\hline Ottawa St. & $0 \%$ & - & $0 \%$ & $8 \%$ & $7 \%$ & $7 \%$ & $25 \%$ & $1 \%$ \\
\hline Charles St. & $8 \%$ & $0 \%$ & - & $0 \%$ & $0 \%$ & $0 \%$ & $18 \%$ & $0 \%$ \\
\hline Grand River & $17 \%$ & $8 \%$ & $0 \%$ & - & $0 \%$ & $0 \%$ & $14 \%$ & $0 \%$ \\
\hline Uptown & $16 \%$ & $7 \%$ & $0 \%$ & $0 \%$ & - & $0 \%$ & $15 \%$ & $0 \%$ \\
\hline Laurier & $15 \%$ & $7 \%$ & $0 \%$ & $0 \%$ & $0 \%$ & - & $18 \%$ & $0 \%$ \\
\hline U of W & $29 \%$ & $25 \%$ & $18 \%$ & $14 \%$ & $15 \%$ & $18 \%$ & - & $33 \%$ \\
\hline Conestoga & $11 \%$ & $1 \%$ & $0 \%$ & $0 \%$ & $0 \%$ & $0 \%$ & $33 \%$ & - \\
\hline
\end{tabular}

The range of travel cost savings for this corridor is 0 percent (where the local service remains the lowest cost option) to 33 percent for travel between Conestoga and the University of Waterloo. 


\section{Corridor 3 Analysis}

In the Corridor 3 analysis, we attempt to identify the cost savings between Ainslie Terminal and northern activity centers. This analysis is a measure of the regional connectivity improvements as a result of iXpress. Table 5 shows the cost reductions. For simplicity, only the reductions in cost from Ainslie Terminal to all northern stops are shown; the cost savings are symmetric.

\section{Table 5. Percent Reduction in Generalized Costs for Trips Originating from the Ainslie St. Terminal (Corridor 3)}

\begin{tabular}{|c|c|c|c|c|c|c|c|c|}
\hline & Fairview & Ottawa St. & Charles St. & Grand River & Uptown & Laurier & U of W & Conestoga \\
\hline Ainslie & $19 \%$ & $21 \%$ & $23 \%$ & $27 \%$ & $26 \%$ & $25 \%$ & $28 \%$ & $16 \%$ \\
\hline
\end{tabular}

The range of cost savings in this case is between 16 and 28 percent.

\section{Identifying Transit Customers Who Benefit from iXpress}

To identify those customers who benefit from the introduction of iXpress, we consider those transit riders who travel in Corridor 2. As shown in Figure 3, there are four trip types that involve some travel through the corridor:

1. Type $\mathrm{I}$ : a trip that both begins and ends in the corridor $\left(\mathrm{O}_{1}, \mathrm{D}_{1}\right)$

2. Type II: a trip that begins outside the corridor on a local route, $L_{1}$, but ends in the corridor $\left(\mathrm{O}_{2}, \mathrm{D}_{1}\right)$ via a transfer

3. Type III: a trip that begins in the corridor but ends outside the corridor $\left(\mathrm{O}_{1}\right.$, $D_{2}$ ) via a transfer to a local route, $L_{2}$

4. Type IV: a trip that begins outside the corridor on a local route, $\mathrm{L}_{1}$, transfers for travel through the corridor, then transfers to a local route, $L_{2}$, to reach the destination $\left(\mathrm{O}_{2}, \mathrm{D}_{2}\right)$

Prior to the introduction of iXpress, all trips through the corridor involved only Route 7. After the introduction of iXpress, each of these trips may involve a transfer to either iXpress or to Route 7, whichever involves the lowest generalized cost. The benefits derived as a result of iXpress differs for each of these trip types. Table 6 quantifies these benefits.

In each case, the potential generalized cost saving is the same-the reduction associated with the iXpress compared to the Route 7 service. The percent reduction, however, varies for each trip type. For those trips that involve transfer to and/or from local service, the time savings along the central corridor represents a smaller percentage of total trip time. This is indicated by the increasing denominator in the third column of Table 6. 


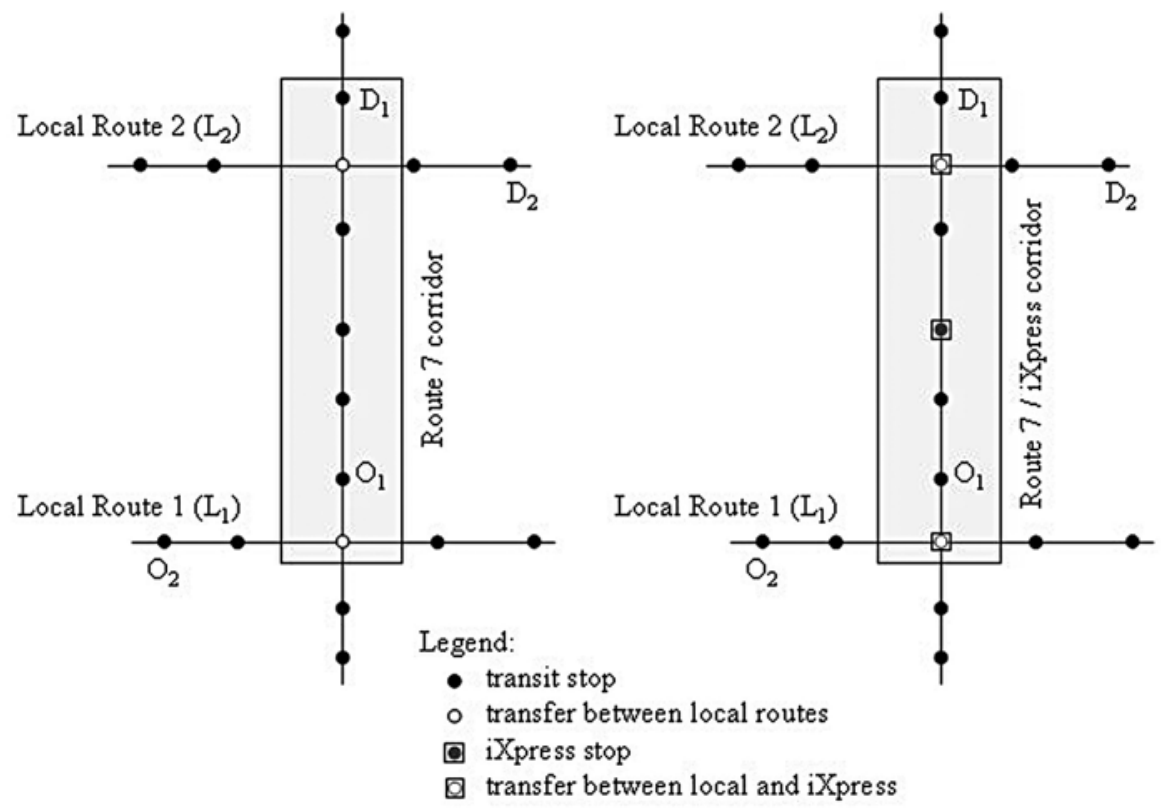

Figure 4. Identifying the Trip Patterns Influenced by the Introduction of iXpress

Table 6. Reductions in Generalized Cost (Total and \%) for Each Trip Type

\begin{tabular}{|c|c|c|c|}
\hline $\begin{array}{c}\text { Trip } \\
\text { Designation }\end{array}$ & Trip & $\begin{array}{c}\text { Cost } \\
\text { Reduction }\end{array}$ & \% Reduction \\
\hline $\mathrm{I}$ & $\mathrm{O}_{1} \mathrm{D}_{1}$ & $\Delta \mathrm{GC}^{7-\mathrm{X}}$ & $\frac{\Delta \mathrm{GC}^{7-\mathrm{X}}}{\mathrm{GC}^{7}}$ \\
\hline $\mathrm{II}$ & $\mathrm{O}_{2} \mathrm{D}_{1}$ & $\Delta \mathrm{GC}^{7-\mathrm{X}}$ & $\frac{\Delta \mathrm{GC}^{7-\mathrm{X}}}{\mathrm{GC}^{\mathrm{L} 1}+\mathrm{GC}^{7}}$ \\
\hline $\mathrm{III}$ & $\mathrm{O}_{1} \mathrm{D}_{2}$ & $\Delta \mathrm{GC}^{7-\mathrm{X}}$ & $\frac{\Delta \mathrm{GC}^{7-\mathrm{X}}}{\mathrm{GC}^{7}+\mathrm{GC}^{\mathrm{L} 2}}$ \\
\hline $\mathrm{IV}$ & $\mathrm{O}_{2} \mathrm{D}_{2}$ & $\Delta \mathrm{GC}^{7-\mathrm{X}}$ & $\frac{\Delta \mathrm{GC}^{7-\mathrm{X}}}{\mathrm{GC}^{\mathrm{L} 1}+\mathrm{GC}^{7}+\mathrm{GC}^{\mathrm{L} 2}}$ \\
\hline
\end{tabular}

\section{Correlating Changes in Generalized Cost to Ridership Gains}

A common economic tool to predict changes in demand as a result of changes in price is to compute elasticity of demand with respect to price. Mathematically, elasticity, E, is defined as: 


$$
E=\frac{\Delta D}{\Delta P}=\frac{\Delta \text { Boardings }}{\Delta G C}
$$

Where: $\quad \Delta D$ is the change in demand, \%

$\Delta P$ is the change in price, $\%$

In our case, we have computed the change in generalized cost for trips between individual origin-destination pairs. As noted in the literature review, ideally these changes in O-D costs could be compared to changes in ridership between O-D pairs. However, due to data limitations, only the change in corridor demand is known. Therefore, to compute elasticities, we utilize these changes in O-D costs to compute a corridor-wide change in generalized cost.

From ridership surveys (Region of Waterloo 2005), the percentage of total trips between each O-D pair is known. Therefore, to compute a corridor-wide elasticity, we calculate a weighted average of reduced generalized costs within the corridor based on travel patterns. Mathematically, this average is given by:

$$
\overline{\Delta G C}=\sum_{O} \sum_{D} T_{O D} \cdot \Delta G C_{O D}
$$

Where: $\quad \Delta G C$ is the weighted average of generalized cost savings, $\$$

$$
\begin{aligned}
& T_{O D} \quad \text { is the observed percentage of transit trips from origin } \\
& \text { to destination }
\end{aligned}
$$

The percentages of trips between origin destination pairs are given in Table 7. From Equation 7, we compute a weighted average generalized cost reduction of 14.1 percent.

This calculation provides the average benefits accrued for travel within the corridor. As noted in the previous section, not all travelers realize this full benefit. Those who make trip type I accrue the full benefit. For trip types II, III and IV, a lesser benefit is realized as a percentage of total trip cost. 
Table 7. Percentage of Travel Between All O-D Pairs

\begin{tabular}{|l|c|c|c|c|c|c|c|c|}
\hline & Fairview & Ottawa & $\begin{array}{c}\text { Charles } \\
\text { St. }\end{array}$ & $\begin{array}{c}\text { Grand } \\
\text { River }\end{array}$ & Uptown & Laurier & U of $\boldsymbol{W}$ & Conestoga \\
\hline Fairview & - & $0.0 \%$ & $9.1 \%$ & $2.0 \%$ & $2.2 \%$ & $2.2 \%$ & $6.1 \%$ & $2.5 \%$ \\
\hline Ottawa & $0.0 \%$ & - & $0.0 \%$ & $0.0 \%$ & $0.0 \%$ & $0.0 \%$ & $0.3 \%$ & $0.3 \%$ \\
\hline Charles St. & $10.3 \%$ & $0.3 \%$ & - & $1.4 \%$ & $3.7 \%$ & $3.4 \%$ & $7.8 \%$ & $1.9 \%$ \\
\hline Grand River & $1.7 \%$ & $0.2 \%$ & $1.7 \%$ & - & $0.0 \%$ & $0.0 \%$ & $2.4 \%$ & $0.3 \%$ \\
\hline Uptown & $0.8 \%$ & $0.0 \%$ & $0.8 \%$ & $0.0 \%$ & - & $0.5 \%$ & $1.4 \%$ & $0.0 \%$ \\
\hline Laurier & $2.9 \%$ & $0.2 \%$ & $2.4 \%$ & $0.2 \%$ & $0.5 \%$ & - & $0.7 \%$ & $0.5 \%$ \\
\hline U of W & $4.4 \%$ & $0.2 \%$ & $4.7 \%$ & $0.5 \%$ & $1.2 \%$ & $1.0 \%$ & - & $4.4 \%$ \\
\hline Conestoga & $3.0 \%$ & $0.0 \%$ & $1.7 \%$ & $0.7 \%$ & $0.5 \%$ & $1.0 \%$ & $6.1 \%$ & - \\
\hline
\end{tabular}

To estimate the benefits realized by travelers making trip types II - IV, we make the following assumption. We assume that the travel cost on each local section is equal to the travel cost in the corridor. Mathematically, we assume:

$$
G C^{L 1}=G C^{L 2}=G C^{7}
$$

This results in trip types II and III experiencing one half the generalized cost reduction and trip type IV experiencing one third the cost reduction.

Again, from travel surveys, we know the percentage of trip makers through the corridor that makes trips of each type. We can then weigh the number of trip takers by their expected reduction in generalized cost to compute a final, corridorwide reduction in generalized costs. These calculations are shown in Table 8.

Table 8. Computing Corridor-Wide Reduction in Generalized Cost

\begin{tabular}{|c|c|c|c|}
\hline Trip type & Number of trip makers (\%) & $\begin{array}{c}\text { Reduction in } \\
\text { generalized cost (\%) }\end{array}$ & $\begin{array}{c}\text { Weighted reduction } \\
\text { (\%GC) }\end{array}$ \\
\hline I & 40.2 & 14.1 & 5.7 \\
\hline II & 22.7 & 7.0 & 1.6 \\
\hline III & 21.6 & 7.0 & 1.5 \\
\hline IV & 15.5 & 4.7 & 0.7 \\
\hline \multicolumn{2}{|r|}{ Corridor-wide, weighted average reduction in GC } & 9.5 \\
\hline
\end{tabular}

Thus, the introduction of the iXpress service in the corridor reduced cost by an average of 9.5 percent.

Finally, to compute elasticity, we calculate the percent change in demand through the corridor. Prior to the introduction of iXpress, there were 15,941 boardings in the Route 7 corridor. When boardings were counted in the corridor after iXpress, 
there were 16,528 boardings on Route 7 and 2,701 boardings on iXpress, for a total of 19,229 .

In the time between the two counts, GRT system ridership grew by 7 percent system wide. To account for this growth, we compute the difference in actual boardings $(19,229)$ to expected boardings $\left(15,941^{*} 1.07=17,057\right)$ assuming ridership on Route 7 grew at the system average. This calculation results in a net growth of 2,172 boardings, or 12.7 percent.

The elasticity of demand with respect to generalized cost can be computed using equation 6 , with $\Delta D=12.7 \%$ and $\Delta P=9.5 \%$. The elasticity, $E$, is then equal to -1.3 .

\section{Understanding Model Results}

Other researchers (as summarized by Litman and Balcombe et al.) typically observed absolute values of short-term elasticities for quality of service, quantity of supply, and price in the range of 0.5 to 0.7 , and long-term in the range of 0.7 to 1.1. The elasticity observed in this research (which can be considered short- to mid-term) is -1.3 , which is inconsistent with the previous findings. We suggest that this surprisingly large value is a result of computing the elasticity of ridership with respect to the composite generalized cost. As noted above, in our case, the introduction of the iXpress results in decreased waiting time, shortened in-vehicle time, and fewer transfers. The results of previous research (Balcombe et al. 2004) suggests a mean elasticity value for ridership with respect to passenger waiting time of -0.64; the same research reports a mean value of elasticity of ridership with respect to in-vehicle time of -0.5 . No study was found to directly compute the elasticity for ridership with respect to transfer times.

Consider the following example. If waiting time were reduced by 10 percent, using an elasticity value of -0.64 , ridership is expected to increase by 6.4 percent. Subsequently, if in-vehicle travel time were reduced by 10 percent, ridership is expected to increase by an additional 5.0 percent. The total increase is calculated as $1.064^{*} 1.05$ or 1.117 or 11.7 percent. Using our generalized cost representation and assuming no transfer, if both in-vehicle time and waiting time were reduced by 10 percent (as in the previous case), then the generalized cost would be reduced by 10 percent. From our elasticity finding of -1.3 , we would expect an increase in ridership of 13 percent, which is consistent with previous findings. 


\section{Sensitivity Analysis}

In assigning the relative weights of travel disutility (equation 3), we assumed the average value presented by Kittelson et al. Further, we assumed a standard value of time of $\$ 8.00$ per hour. To assess the sensitivity of our findings to these assumed values, we present the following analysis. We recomputed the percent reduction in generalized cost in the corridor while varying each of the assumptions from a minimum of 0.5 times the initial value to a maximum of 1.5 times the initial value. For example, in the initial analysis, we assume waiting time is considered 2.1 times as onerous as in-vehicle time. To test the sensitivity, we compute the reductions in generalized costs if waiting time ranged from 1.05 times to 3.15 times as onerous as in-vehicle time. Similarly, we test values for transfer time that range from 1.25 to 3.75. Finally, we compute percent reductions in generalized travel costs for ranges of value of time from $\$ 4.00$ to $\$ 12.00$. The results are shown in Figure 5 .

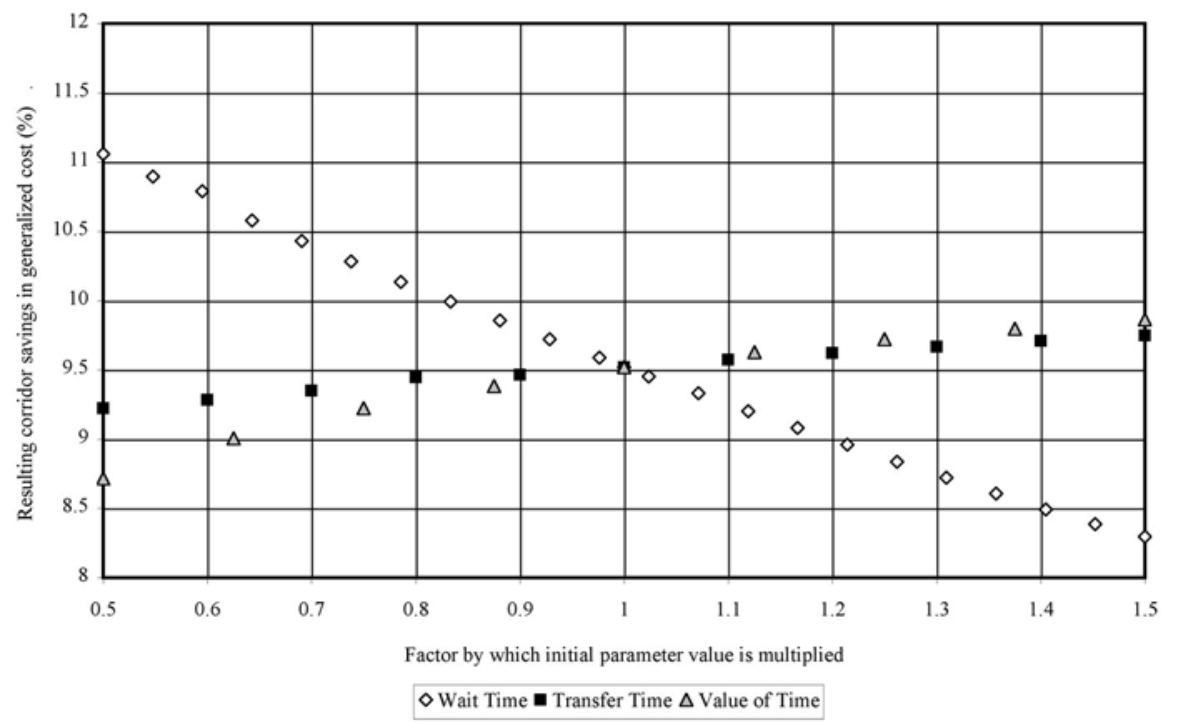

Figure 5. Sensitivity of Generalized Cost Reductions to
Parameter Assumptions

When all the initial parameters are multiplied by 1.00 , the reductions in generalized cost equal the result presented in the previous section, approximately 9.5 percent. In analyzing each parameter, it is noted that the reductions in generalized costs are most sensitive to the relative weight for waiting time. If we reduce the relative importance of waiting time in calculating generalized cost, then travelers 
in the corridor experience savings of 11.1 percent. If we increase the importance of waiting time, then the benefits accrued from iXpress are reduced to approximately 8.3 percent in the corridor. This is logical as the introduction of iXpress has the least impact on waiting times in this corridor.

Varying the importance of transfer times has little effect on the net benefits associated with iXpress, with the generalized costs savings varying from 9.2- 9.8 percent. Obviously, as transfer times become relatively more important, generalized costs savings increase. Similarly, the magnitude of corridor savings increases with increased of value of time, but only marginally. If we assume travelers have very low value of time, then the travel cost savings falls from the initial value of 9.5 percent to approximately 8.7 percent. Under the assumption of high value of time, $\$ 12.00$ per hour, then the travel cost savings increase to 9.8 percent.

\section{iXpress Service Performance and Upgrade Plans}

During the planning of iXpress, Grand River Transit forecasted ridership projections for several periods: immediately after service initiation, at the time when all supporting technologies for iXpress had been implemented, and one year after this full implementation. These BRT technologies include transit signal priority (TSP) along its corridor, AVLS to support real time arrival information at all locations, a web-based trip planner, and an interactive voice response (IVR) system to provide passenger information. At the time of the most recent data collection, several delays had precluded the full implementation of these technologies. Table 9 summarizes how ridership (average weekday boardings) forecasts compare with actual ridership.

Table 9. Projected and Actual Ridership Values

\begin{tabular}{|l|c|c|c|}
\hline \multicolumn{1}{|c|}{ Period (year) } & Projected & Actual & $\begin{array}{c}\text { Ratio (actual/ } \\
\text { projected) }\end{array}$ \\
\hline Service initiation (Sept. 2005) & 3800 & 3500 & 0.92 \\
\hline $\begin{array}{l}\text { Service with supporting } \\
\text { technologies }\end{array}$ & 5000 & 5637 & 1.13 \\
\hline $\begin{array}{l}\text { One year after full technology } \\
\text { implementation }\end{array}$ & 5700 & n/a & n/a \\
\hline
\end{tabular}

Based on the success of the iXpress, the Region has undertaken an Environmental Assessment to determine the feasibility and optimal design of an upgraded, rapid transit system which will be operated on longitudinally separated right of way. The process is ongoing, with final approval slated for 2009. 


\section{Conclusions}

This paper presents a methodology to assess the impacts of express bus service in areas with existing transit service. The method presented is based on utility theory, the traditional model used in mode choice models. However, the application in this case is done for individual origin-destination pairs in three corridors such that micro-level generalized cost components (waiting time, in-vehicle time, and transfer times) can be readily computed before and after the introduction of the express service. We find cost savings for individual O-D pairs that range from $0 \%$ (local service remaining the best option) to as high as 33 percent.

Next, using survey data that provide travel volumes between O-D pairs, we aggregate the O-D cost savings to a corridor-wide average travel cost savings for the highest ridership area. We calculate an average travel cost savings of approximately 9.5 percent for all riders as a result of the iXpress. The benefits of computing this corridor-wide cost reduction is that corridor elasticity can now be computed based only on the changes of boardings in the corridor, rather than a change in O-D volumes. When combined with an increase in demand in the corridor of 12.3 percent, this cost reduction suggests an observed elasticity of demand with respect to price of 1.3 .

Finally, we test the sensitivity of our travel cost savings to the assumed weights of waiting time and transfer time, as well as value of travel time. All of these variables display the expected relationships: travel costs savings decrease as waiting time becomes more important (because the express service contributes little to waiting time savings); travel costs savings increase with transfer times becoming more important, and with increasing value of time. The magnitude of each of these changes suggests that the model is largely insensitive to these parameter values.

\section{Endnotes}

${ }^{1}$ Many Canadian metropolitan areas have so-called Regional governments that, in essence, act as a bridge between Provincial and municipal governance. The Regional Municipality of Waterloo has legal responsibility to develop a Regional Official Plan which is consistent with the Province in its strategic planning goals, and sets the objectives for municipal plans. The Region also operates Grand River Transit, the region's transit service. 


\section{References}

Ben-Akiva, M., and S. R. Leman. 1985. Discrete Choice Analysis: Theory and Application to Travel Demand. Cambridge, MA: MIT Press.

Balcombe, R., R. Mackett, N. Paully, J. Preston, J. Shires, H. Titheridge, M. Wardman, and P. White. 2004. The Demand for Public Transport: a Practical Guide. TRL report, TRL593. www.DemandForPublicTransport.co.uk, accessed 13 May 2008.

Casello, J.M. 2007. Transit competitiveness in polycentric metropolitan areas. Transportation Research Part A 41(1): 19-40.

Holmgren, J. 2007. Meta-analysis of public transport demand. Transportation Research Part A 41(10): 1021-1035.

Kittelson and Associates, et al. 2003. TCRP Report 100: Transit Capacity Quality of Service Manual, 2nd Edition. Washington DC: Transportation Research Board.

Kopp, J. C., et al. 2006. Transit attractiveness: Systematic approach to transit performance measurement. Journal of the Transportation Research Board 1986: $11-20$.

Lancaster, K. 1966. A new approach to consumer theory. Journal of Political Economy 74: 132-157.

Litman, T. 2004. Transit price elasticities and cross-elasticities. Journal of Public Transportation 7(2): 37-58.

Ortuzar, J., and L. Williamson. 2001. Modelling Transport, 3rd Edition. Chinchester, UK: John Wiley \& Sons Ltd.

Region Municipality of Waterloo. 2003. Regional growth management strategy: planning our future, Waterloo, ON, Canada.

Region of Waterloo. 2005. iXpress ridership survey, Waterloo, ON, Canada.

Taylor, B. D., and D. Miller. 2004. Analyzing the determinants of transit ridership using two-stage least-squares regression on national sample of urbanized areas. Presented at 83rd Annual Meeting of the Transportation Research Board, Washington, DC.

Vuchic, V. 2005. Urban Transit: Operations, Planning and Economics. Hoboken, N): John Wiley \& Sons, Ltd. 


\section{About the Authors}

Dr. Jeff Casello (jcasello@fesmail.uwaterloo.ca) is an Assistant Professor in the Department of Civil and Environmental Engineering and the School of Planning at the University of Waterloo. His interests lie in urban transportation systems and their impacts on healthy and economically viable urban areas. As such, he conducts research on the design and operation of public transportation systems. His professional experience includes six years as a highway designer for the New York State Department of Transportation, and recurring consultant work for several transit agencies and metropolitan governments.

Dr. Bruce Hellinga (bhellinga@uwaterloo.ca) received B.A.Sc. and M.A.Sc. degrees in Civil Engineering from the University of Waterloo in 1989 and 1990, respectively, and Ph.D. in Civil Engineering-Transportation from Queen's University in Kingston, Ontario, in 1994. Currently, he is an Associate Professor in the Department of Civil and Environmental Engineering at the University of Waterloo, Waterloo, Ontario. He has authored or coauthored more than 90 technical papers and reports reflecting his research interests which include traffic engineering and control, traffic and transit modeling, safety and ITS. He has received financial support for these research activities from a number of public and private sector agencies including the Natural Sciences and Engineering Research Council of Canada and federal, provincial, and municipal transportation agencies. 